\title{
LA CENSURA A LA CULTURA EN EL RÉGIMEN BOLIVARIANO
}

\author{
CENSORSHIP TO CULTURE \\ IN THE BOLIVARIAN REGIMEN

\section{Luis CHESNEY LAWRENCE} \\ Universidad Central de Venezuela \\ lchesney@cantv.net
}

«Todo fue un despelote. Quisimos hacer una copia de la revolución cubana y nos caímos. Los dirigentes estaban todos confundidos. La caída de Batista, la política de Betancourt y la escasa claridad ideológica nos volvieron locos». Héctor Castro, Concierto en re mayor para dos panas burdas (1986)

Resumen: Este artículo trata de la censura y de sus efectos sobre algunas manifestaciones culturales en Venezuela durante el régimen bolivariano (1999-2010). El objetivo que se planteó esta investigación fue el de conocer y entender la verdadera naturaleza de esta censura en la cultura venezolana, las entidades utilizadas, los procesos establecidos y las estructuras ideológicas que la sustentan, para lo cual se utilizó una metodología documental de datos y casos reconocidos. 


\begin{abstract}
This article deals with censorship and its effects on some cultural manifestations in Venezuela during the bolivarian regime (1999-2010). The objective of this research was to know and to understand the real nature of this censorship in the Venezuelan culture, the entities utilized, the preocess established in order to implement it, and the ideological structures that sustains it, for this, a documentary methodology of data gathered and of recognized cases was used.
\end{abstract}

Palabras claves: Venezuela. Bolivariano. Cultura. Censura. Siglo XX

Key Words: Venezuela. Bolivarian. Culture. Censorship. XXth century.

\title{
1. INTRODUCCIÓN
}

Si es una tarea esencial en la investigación de cualquier cultura nacional conocer cabalmente a sus autores y obras, ahora también deberá sumarse el conocer esta historia con una visión más profunda y moderna, especialmente cuando los estudios han sido escasos y muy poco conocidos. No obstante, tampoco debería extrañar el olvido que puede subyacer en estos recuentos. En el caso de Venezuela pareciera ocurrir que estas ideas relativas a la censura y a sus efectos sobre su cultura y su sociedad se cubren de un sospechoso espectro deformado.

Un país se imagina a sí mismo por las historias que relata y que permanecen en el recuerdo. Por esta razón, las historias sobre Venezuela provinieron principalmente de las fuentes de su cultura, las artes, la literatura, la radio, el cine y la televisión. Así se fue creando el discurso cultural del país, la imagen de sus hombres y mujeres, la de sus ideas y la de sus costumbres, paulatinamente, en el devenir de su propia y conflictiva historia. En definitiva, así se construyó y así es Venezuela, desde este sustrato cultural que se ha prolongado hasta hoy día. De esto trata este artículo, de la censura y de sus efectos sobre algunas manifestaciones culturales durante el régimen bolivariano 1999-2010. No es ésta una nueva historia de la cultura ni tampoco de su revisión, sino que se propone alcanzar un conocimiento más cabal de la misma, entendiendo episodios esenciales ocultos o muy poco conocidos, como es el de la censura. La metodología empleada tomó en consideración una intensa revisión documental de datos y casos reconocidos, de manera que pudiera ser consultada sin mayores problemas.

El tema de la censura se intenta explicar desde la perspectiva de la Teoría de los Motivos y Estrategias, de Ángel Berenguer (2008: 16), que, aunque di- 
señada para las artes escénicas, también puede presentarse como los motivos y estrategias de la censura a la cultura, lo cual implica no sólo interpretar y reconocer las estructuras de poder, el poder real y los mecanismos a los que creen tener derecho los que limitan la producción artística y cultural nacional, afectando incluso a su sociedad. En este sentido, como señala Berenguer (2008: 17), un producto, cuya expresión cultural para los círculos de poder puede significar una agresión, aún siendo imaginaria, despierta el interés del poder de turno que se interesa por conocer estas formas y contenidos y reacciona utilizando el poder de que dispone, que considera legítimo, para juzgar como indeseable su obra, producto o autor, y condenarlo al silencio, agraviándolo y despreciándolo en las esferas económicas, sociales o judiciales de que dispone.

A la luz de su historia pasada y presente este tema se ve como ineludible, ya que en una investigación anterior publicada se exploró la censura en el teatro durante el período 1900-1950, lo que de alguna manera constituye la primera parte de la historia oculta del teatro venezolano, aún por develar completamente (Chesney, 2008), que ahora se amplía presentando una fracción de lo ocurrido durante el régimen bolivariano.

\section{1999-2010: LA CENSURA BOLIVARIANA A LA CULTURA}

El ensayo comenzado en 1999, encabezado por Hugo Chávez Frías, intentó corregir y ajustar los errores de gobiernos anteriores, moviéndose en dirección contraria. Sin embargo, como explica Gil Yepes (2009: 29), el país entró en una profunda crisis general y fue retomando los aspectos negativos heredados del pasado, siempre según el criterio personal del Presidente, sin considerar la opinión de la población.

\subsection{El combate de la boa}

La llegada del siglo XXI trajo consigo grandes cambios en el campo tecnológico, entre los que resalta en la esfera de esta investigación la comunicación. En el caso venezolano, el gobierno bolivariano ha adoptado la actitud de enfrentarla tanto desde el intento por apropiarse de algunos medios como de promover muchos a su favor, aunque los contactos por celulares, por internet, e-mails y por las redes sociales ha sido una manifiesta respuesta a estos intentos; aunque esta acción del régimen se ha extendido a instituciones 
sociales importantes — léase Asamblea Nacional y Poder Judicial—, así como de hostigar y reprimir fundamentalmente a la televisión.

En este mismo sentido, no se puede negar que el proceso de la censura en este gobierno es estructural, organizado, que funciona como una maquinaria y que alcanza a todas las instancias de las instituciones del país y de la sociedad, paradojalmente también al propio Presidente. Desde el año 2002, cuando comienzan las grandes protestas en contra del gobierno, será el momento en que se inicia también la despersonalización de la gente a través de su desprestigio individual, al tratarlas en forma despectiva - con apodos como «escuálidos» o «pitiyankis», entre otros-, iniciando así un proceso de deshumanización que llevó luego, consecuencialmente, a criminalizarlos, a ser acusados penalmente de graves cargos en contra del Estado. El primer hecho noticioso relevante ocurrió en el año 2000 cuando se suspendió, sin razones claras ni explicadas, un programa televisivo matutino de gran audiencia del periodista Napoleón Bravo. En 2005, también fue sacado del aire el programa Dossier, del periodista Walter Martínez, en el canal estatal Venezolana de Televisión (VTV), ambos adeptos al gobierno, lo cual se hizo, según relata Wladimir Serrano López (2006), en la pagina web del gobierno - ww.aporrea.org - porque el periodista había formulado declaraciones a otro periódico prooficialista -Última Noticias del 21/09/2005: 20-, en donde criticó la presencia de quintas columnas en el gobierno, la corrupción y analizó la tesis del «chavismo sin Chávez» que en esa época se manejaba en sectores del gobierno.

Estos hechos han hecho pensar a periodistas, afines al gobierno, que no están de acuerdo con estos mecanismos, que dentro del periodismo del Estado existen dos vertientes al respecto, con muchos matices (Lubrio, 2009): «Una escuela antigua, que asume que, si en nuestros medios se deja de hablar sobre algo, la gente automáticamente dejará de hablar del asunto y seguirán viviendo sus vidas sin cuestionar nada, cual robots o como si fueran ciudadanos de una dictadura norcoreana». Es el llamado «periodismo institucional», y es el que domina en los departamentos de prensa y relaciones públicas de los Ministerios, así como en casi todos los medios del Estado, aunque advierte que «quienes nos formamos en medios alternativos, metidos de cabeza en Internet o trabajando con comunicadores sociales que piensan distinto, entendimos que la gente hoy BUSCA la información, y no se conforma únicamente con lo que se les da». De esta forma, cada cual va sacando sus conclusiones sobre qué medios le dicen la verdad y cuáles le ocultan la información. Lubrio también reseña otros casos en donde esta situación se ha tratado de solventar, como fue la de los medios alternativos dentro del Es- 
tado, con posiciones revolucionarias, pero críticas. Entre 2006-2007, se reseñan sólo los casos de Ávila TV y YVKE Mundial, que no tuvieron éxito; «lamentablemente, diversas situaciones que ocurrieron en Ávila TV y que forzaron a dos cambios de directivas» le hicieron peder su perfil crítico. En el caso de YVKE Mundial, en su página web www.radiomundial.com.vel, se intentó hacer una crítica constructiva y de análisis dentro del proceso bolivariano y cuando algún funcionario del Estado llamaba para quejarse por alguna noticia incómoda, la directora, Cristina González, defendía a su personal y mantenía la nota periodística. Pero la emisora YVKE Mundial fue transformada en 2009: «la sustitución de González causó que se impusieran políticas absurdas que en nada ayudaron a este proceso», y en la página web las noticias críticas eran sustituidas por comunicados de Empreñen, los noticieros de YVKE fueron reducidos, programas de radio combativos fueron eliminados $\mathrm{y}$, paulatinamente, unos 15 periodistas y comunicadores renunciaron.

Tal vez, el hecho más significativo se ha dado cuando el diputado del partido del gobierno, Darío Vivas, propuso el día 26 de enero de 2010, ante la Asamblea Nacional, que se borraran de las actas de dicho cuerpo legislativo todas palabras ofensivas que se han pronunciado en contra del Presidente de la República; idea que afortunadamente no tuvo mayor resonancia, pero que muestra uno de los extremos a que se puede llegar en torno a la censura.

La estrategia general aplicada a los medios $-\mathrm{y}$, en general, al país-, según Tulio Hernández (2007), se sustentaría en la analogía que existe entre las dictaduras y estos nuevos regímenes: «suelo utilizar las imágenes del zarpazo del tigre y la boa constrictor». Las dictaduras, generalmente resultantes de golpes de Estado, son como el zarpazo del tigre, «actúan rápidamente y por sorpresa, son sangrientas». Desde esta perspectiva, ya desde el año 2001, cuando comienzan las protestas masivas en contra del gobierno y éstas son vistas ampliamente en la televisión, éste se da cuenta de la importancia de los medios de comunicación masivos e implementa una estrategia impaciente para tomar posesión de ellos y deteriorar la libertad de expresión y de la comunicación con el fin de producir un clima de intimidación y de hostilidad hacia ellos, que se extremó en 2010, año electoral - evento en que el gobierno perdió un $47 \%$ del electorado-, en el cual resaltan (1) la utilización impetuosa de las cadenas presidenciales, (2) ampliación de su propio espacio comunicacional, (3) utilización de instrumentos legales y administrativos para limitar la labor de los medios privados, (4) persecución y represión a los medios y los periodistas y (5) el desprestigio y descrédito de los periodistas. 
En cuanto a las cadenas presidenciales, el Sindicato Nacional de Trabajadores de la Prensa (2010: 1-9), teniendo en cuenta varios estudios efectuados, expresa que, desde el 2 de febrero de1999 hasta el 31 de marzo de 2009, el Presidente había encadenado a los medios por 1.207 horas con 6 minutos y 54 segundos, con un total de 1.877 cadenas, es decir, equivalía a más de 50 horas ininterumpidas de cadena; igualmente otro estudio de la Universidad de Los Andes sobre el aparato comunicacional del gobierno, citado por este ente gremial, refiere que «la voz del Presidente permanece en el aire todos los días por unos 90 minutos», a través de cadenas o declaraciones en actos públicos, sin incluir las horas de su programa Aló Presidente (que no se considera cadena) que mantiene un promedio de más de 4 horas semanales en promedio durante estos 10 años, en donde - como ha señalado el Instituto de Prensa Internacional (2009: 1-4) - el Presidente utiliza «una retórica cada vez más agresiva e incendiaria». La audiencia de estas cadenas y alocuciones, según estadísticas especializadas, no sobrepasa el 2,5\% de la población. En su jerga popular se ha encargado de glorificar a héroes internacionales y nacionales de dudosa reputación, entre otros, a Idi Amin, Maisanta o El Chacal. Como señala Manuel Caballero (2010: 4-8), «usa en sus interminables alocuciones públicas el lenguaje de los porteros de burdel».

En relación con la ampliación del espectro comunicacional del régimen, Fabiola Soto (2008) informa que el gobierno, al llegar al poder en 1999, apenas contaba con la señal de Venezolana de Televisión, una señal de radio AM (sólo para el centro del país) y una señal con frecuencia modulada, además de la Agencia de noticias Venpres. En 2008 se contabilizan más de 400 espacios de comunicación, de los cuales 163 eran radios, 143 radios pagadas a comunidades, 18 plantas de televisión comunitarias con señal abierta, 72 periódicos comunitarios financiados por el gobierno y los canales de televisión que administra directamente como Venezolana de Televisión, Vive Televisión, Telesur, CMT, Canal de la Asamblea Nacional, la Agencia Bolivariana de Noticias, el diario Vea y numerosos sitios en Internet.

Con respecto a los instrumentos legales y administrativos, en 2004 se aprueba la Ley de Responsabilidad Social en Radio y Televisión (Ley Resorte), que otorga amplias facultades administrativas para el control y para efectuar sanciones a la Comisión Nacional de Telecomunicaciones (CONATEL). Ambas intentan promover y garantizar el funcionamiento de la radio y televisión, en un contexto cultural y nacional, pero que se han visto cuestionadas incluso por sectores afectos al gobierno, considerada instrumento de censura. Así, tan sólo por citar algunos de sus artículos, se puede mencionar que la programación deberá adecuarse a los contenidos de sexo, salud, lenguaje y vio- 
lencia, permitidos en los horarios de «todo usuario» $\mathrm{y}$ «supervisado» (art. $6 \mathrm{y}$ 7), de sólo 12 horas, hasta las 7 p.m. (art. 7), otorga 70 minutos semanales de espacios gratuitos para el Estado (art. 10), para ser transmitidos por los servicios de televisión por suscripción, se ponen trabas a los jóvenes que aspiren a incursionar en el mundo de la producción independiente, al exigirles experiencia además de demostrar capacidad para realizar producciones, como condición para inscribirse en CONATEL (numeral 2, art. 13), se contempla un porcentaje superior para la producción extranjera que para la producción nacional (art. 14), que ocupa un total de 10,2 horas al día, frente a 13,8 horas diarias de la extranjera, la producción nacional independiente es de tan sólo 5,8 horas al día, sobre la democratización de los medios (art. 14) (Aporrea, 2004). Aun con lo punitiva que era la original ley Resorte, en septiembre de 2009, la Asamblea Nacional procedió a reformarla para limitar aún más los mecanismos de reducción de espacios, que ahora obliga a los productores y usuarios a recibir más información del gobierno; de las 5 horas y media asignadas anteriormente para la producción nacional independiente, ahora se estipuló que sólo serían 3 horas y media y, además, prohíbe los mensajes difundidos por personas naturales que tengan alguna relación de subordinación con la emisora con la cual contratan, lo cual apunta directamente al sector de las radios, así, en enero de 2010, ya CONATEL llevaba cerradas 34 emisoras de radios muy populares (Reyes, 2010: 1-4) y el Sindicato Nacional de Trabajadores de la Prensa (2010) anunciaba que este organismo obligaba a 226 canales de televisión por cable (de un total de 391, de los cuales 286 tiene carácter internacional) a transmitir las cadenas oficiales.

En el fondo de esta estrategia estaba la mirada puesta en la estación de televisión RCTV, opositora al gobierno, cuya señal libre fue retirada por el gobierno y despojada de sus equipos en mayo de 2007 por la ley Resorte y que continuó con sus programas con el canal RCTV internacional, que alcanzó una alta audiencia, produciendo el efecto de que ahora el $40 \%$ de la clase social $\mathrm{E}$ se incorporó al sistema de cable, pero que debió cerrar también esta señal. El argumento utilizado en el primer cierre fue que el gobierno requería una señal de amplio alcance nacional para crear una señal de servicio público y al vencerse la concesión de este canal no se renovó. Con esta señal nace el canal TVES, tomando la red de transmisión de RCTV, pero que al cabo de tres años demostró su fracaso comunicacional, con una audiencia que nunca superó el $2 \%$ y con fuertes escándalos de corrupción entre su personal (Aporrea, 2009).

Por esta razón, en el siglo XXI, el tema de la censura lleva directamente al de la libertad de expresión e información y al de los derechos humanos. 
Andrés Cañizales (2010: 18), señala entre éstos, la Ley Resorte por su acentuado carácter punitivo y de censura, administrada por el gobierno a su capricho y que en la realidad no ha producido cambios en la calidad de los medios. También señala al Código Penal, instrumento legal muy retrógrado al punto de «que en Venezuela sigan vigente las penas de prisión por lo que se podría llamar «delitos de opinión». Gran parte de estas acciones se encuentran comprendidas en el denominado Proyecto de Hegemonía comunicacional, anunciado por el ex ministro de Información Andrés Izarra (2008): «Para el nuevo panorama estratégico que se plantea, la lucha que cae en el campo ideológico tiene que ver con una batalla de ideas por el corazón y la mente de la gente. Hay que elaborar un nuevo plan, y el que nosotros proponemos es que sea hacia la hegemonía comunicacional e informativa del Estado». Construir hegemonía en el sentido gramcsiano.

Durante el mes de abril de 2010, sin embargo, la juventud del partido de gobierno anunció que esta teoría había fracasado al informar en un comunicado oficial que «es evidente el fracaso de los intentos de imponer la hegemonía comunicacional revolucionaria» y el «retraso del desarrollo de la profundización ideológica de nuestra Revolución en los cuadros jóvenes», motivos por los cuales se plantearon relanzar un nuevo esquema de comunicación conformando la denominada «Guerrilla mediática» y de la «Vanguardia de Educación Media», como aparece señalado en el texto Documento político conformación del frente de juventudes bicentenarias 200, a través de los cuales intentarán «interpretar los códigos de la juventud en estos momentos de ataques mediáticos» (Reyes, 2010b: 1-4; Documento político del Frente de Juventudes Bicentenarias 2000; y Rodríguez, 2010).

El informe de la Comisión Interamericana de Derechos Humanos (CIDH, 2009) sobre Venezuela — cuya presidenta es venezolana y designada por el gobierno bolivariano - incluyó casos que están en la Corte o que fueron resueltos por ésta, en los cuales se considera que hubo violación de derechos humanos. Venezuela es uno de los países con más casos en la Corte, diez, todos resueltos contra el Estado, además de la data recogida de medios privados y gubernamentales, incluyendo las observaciones del gobierno, aborda prácticamente todos los dominios aquí analizados, desde una óptica internacional, precisándolos y reafirmándolos. Las decisiones de la Corte, según el abogado especialista Héctor Faúndez (Giusti, 2010: 1-2), son respetadas por los gobiernos y las cumplen, como se ilustra cuando en Chile se sentenció al Estado por la prohibición de exhibir la película La última tentación de Cristo, en donde no sólo se le obligó a retirar la censura, sino incluso a modificar su Constitución para que no se repitiera tal situación. El Proyecto 
de Informe Democracia y Derechos Humanos en Venezuela fue aprobado por la Comisión el 7 de noviembre de 2009, en el marco de su $137 .{ }^{\circ}$ período ordinario de sesiones. Sobre la censura y los medios en Venezuela, su resumen ejecutivo (CIDH, 2009: xiii-xiv) es muy explícito cuando señala, entre otras cosas, que:

18. La CIDH observa que en los últimos meses se incrementaron los procesos administrativos sancionatorios contra los medios de comunicación críticos del gobierno. De manera particular, preocupa a la Comisión que en varios de estos casos, las investigaciones y procedimientos administrativos se iniciaron luego de que las más altas autoridades del Estado llamaran a las entidades públicas a actuar contra Globovisión y otros medios independientes y críticos del gobierno.

19. La Comisión también ha verificado la existencia de casos de censura previa como prototipo de violación extrema y radical de la libertad de expresión en Venezuela. Como ejemplo de lo anterior, en el presente informe se analiza la prohibición establecida contra publicidad contraria a un proyecto de interés gubernamental, publicidad que había sido emitida por Cedice y Asoesfuerzo.

20. Este informe también analiza los efectos sobre el derecho a la libertad de expresión del proceso iniciado en julio de 2009 para establecer la posible revocatoria de las concesiones otorgadas a 240 emisoras de radio, así como de la decisión de ordenar la suspensión de la trasmisión de 32 radioemisoras... Asimismo, la Comisión mira con preocupación que las afirmaciones del Ministro del Poder Popular para las Obras Públicas y Vivienda sugieren que la línea editorial de estos medios sería una de las motivaciones para la adopción de las revocatorias o las medidas de cierre, independientemente de las razones técnicas que se esgrimen en los correspondientes actos administrativos.

He aquí el fondo de esta cuestión, que, en años siguientes, se dirigirá también a los medios y a los periodistas. El abogado de la ONG Foro Penal, Alfredo Romero (2010), expresa que estas son un «esquema de represión que criminaliza la protesta» y que violan los derechos humanos de los periodistas y cuya recopilación ha dado como resultado un expediente que se consigna actualizado cada seis meses en el Tribunal Penal Internacional de La Haya, como una reiterada práctica gubernamental para impedir el derecho al disenso y en cuyas imputaciones a los manifestantes siguen un esquema patrón que contempla «instigación a delinquir, instigación al odio, obstaculización de las vías públicas y perturbación del orden público, lo que daría como resultado penas de hasta 5 años». 
Esto se puede ilustrar con lo ocurrido a doce periodistas de la Cadena Capriles que resultaron heridos, ocho de ellos de consideración, cuando se encontraban en la esquina Veroes entregando volantes alusivos a su rechazo a la Ley de Educación, cuando fueron agredidos el 13 de agosto de 2009 por un grupo de personas que se identificaron como simpatizantes de la revolución, quienes se acercaron y los agredieron con golpes, aduciendo que estaban en «territorio del pueblo» y que ellos eran «defensores de la oligarquía». Tras la agresión, algunos voceros del Gobierno nacional y del Partido Socialista Unido de Venezuela (PSUV) han tratado de justificar la agresión, alegando que éstos actuaron como «agentes políticos y no como periodistas», provocando a las personas que se encontraban cerca. Han alegado incluso que los agresores pudieran haber actuado en legítima defensa. El presidente de la República indicó que los atacantes actuaron para defenderse de unos periodistas que no actuaban como tales sino como militantes políticos que buscaban provocar, para luego emplear cualquier respuesta defensiva en contra del Gobierno (Piñero, 2009).

Sobre estos aspectos, la CIDH (2009: x, xi, xvii) también ha dado su pronunciamiento:

7. La CIDH también identifica en el presente informe una preocupante tendencia a castigar, intimidar y agredir a personas a manera de represalia por haber hecho público su disenso con las políticas oficiales. Esta tendencia afecta tanto a las autoridades de la oposición como a ciudadanos que han ejercido su derecho a expresar su disconformidad con las políticas adelantadas por el gobierno. Las represalias se realizan tanto a través de actos estatales como de actos de acoso y violencia provenientes de personas civiles que actúan al margen de la ley como grupos de choque. La Comisión nota con preocupación que se ha llegado al extremo de iniciar procedimientos penales contra disidentes, acusándolos de delitos comunes con miras a privarlos de su libertad en virtud de su posición política.

\subsection{La censura bolivariana en la cultura}

No debe extrañar que en el campo de la cultura estas mismas estrategias se hayan utilizado en contra de grupos y de los propios artistas. El sector cultural refleja palmariamente esta situación. Así, en un breve repaso por algunas de estas áreas, se puede señalar el caso del Ballet Contemporáneo de Caracas, que durante diez años trabajó en coordinación con el Ministerio de la Cultura, y que, en el 2009 y sin mayores explicaciones, se le redujera su pre- 
supuesto y lo desalojasen de su sede en el Teatro Alberto de Paz y Mateos, según su directora María Eugenia Barrios, porque este ballet «no está dentro de los lineamientos de las políticas culturales y además no presenta un real impacto social y comunitario». Según ella fue error de la mesa técnica que designó el Ministerio, «esto fue algo que dictó la mesa técnica sin ni siquiera avisarnos ni llamarnos» (Falcón, 2009), al referirse a una mesa integrada por colegas de su mismo campo a quienes el gobierno les dio la tarea de evaluar sus presentaciones, actitud que se repetirá en otros campos y que se analizará con mayor detalle más adelante.

Igualmente, la ONG Gente de la Cultura-Medios ha llamado la atención sobre la censura en los artes visuales. En primer término, aparece la censura a eventos internacionales. El 31 de enero 2003, el jurado designado para seleccionar la representación de Venezuela en la 50 Bienal de Venecia, determinó que las obras City Rooms de Pedro Morales y La Colmena de Javier Téllez, no cumplían con las exigencias de calidad, pertinencia y factibilidad de sus proyectos. Téllez a los pocos días declinó la invitación, argumentando razones éticas «como venezolano y como artista responsable ante nuestra realidad» y, luego, vino el veto del Consejo Nacional de la Cultura (CONAC) a Pedro Morales porque el contenido de su obra era una agresión a la imagen del país. De esta forma la Bienal se quedó sin representación oficial del país. Otros ejemplos de artista censurado, que señala en su informe Óscar Lucien (2006: A-9), es el de Nelson Garrido y la censura en el Museo Alejandro Otero a la obra Mi delirio sobre el chimbo raso.

Luego, en relación a la obra urbana y, en general al patrimonio cultural del país, se señala el abandono del patrimonio de la ciudad de Coro, como lo expresa Luis Dovale Prado (2009: 25) en relación con el Archivo General del Estado Falcón y otros monumentos que por décadas permanecen dispersos y en vías de deterioro, considerados «patrimonio histórico de los bienes inmuebles antiguos, las obras de arte y otras reliquias de reconocido valor artístico y cultural... [evidenciando] la situación de abandono en que se encuentran los archivos del Concejo Municipal, Registro Principal, Prefecturas, Gobernación del Estado, Archidiócesis» así como el mismo casco colonial de la ciudad. Este hecho ha sido denominado «memoricidio» contra la historia de esta región, concluyendo que «todo esto es un contrasentido inaceptable a la luz de nuestro proceso revolucionario que refrenda en su Constitución Bolivariana la obligación de proteger el patrimonio», al punto de recibir una amenaza de UNESCO para eliminarle el título de Patrimonio de la Humanidad y recordando, además, la investigación hecha después de la invasión de Irak, sobre el saqueo de sus sitios históricos y museos por Fernando Báez 
(2004: 22), en donde advierte sobre «el fantasma de la desaparición del vínculo memorial... Un libro se destruye con ánimo de aniquilar la memoria que encierra, es decir, el patrimonio de ideas de una cultura entera».

Además, se pueden mencionar el descuido de las obras de Otero Abra Solar, la Fisicromía mural de Cruz-Diez en la Plaza Venezuela, la obra de Zapata y la Esfera roja de Soto en la autopista del este, ex profeso, como también el caso del monumento a Cristóbal Colón del maestro Rafael de la Cova (1900), vandalizada a la vista de todos por un grupo oficialista que lo acusó de ser «genocida», queriendo sustituirla por una de Ezequiel Zamora. En octubre de 2005 comenzó la demolición del Muro de inducción cromática de Carlos Cruz Diez, regalo hecho por el artista en 1991 al pueblo de La Guaira, que quería ocultar con una obra moderna el muro gris del área perimetral del puerto de 2100 metros, y que el artista expresó que «era una obra para solucionar un problema urbano», por lo que la obra había quedado registrada como bien cultural nacional, que ahora la cubre un nuevo muro de rejas que el presidente de la empresa del Puerto del Litoral Central, Pedro Arroyo, mandó colocar como parte de un plan maestro de desarrollo del puerto que nunca se ha concretado; así como también la desaparición de los archivos de las obras de arte en las instituciones oficiales, incluyendo la colección de la industria petrolera (PDVSA), la degradación de espacios culturales para transformarlos en lugares de proselitismo político, como es el caso del Teatro Municipal y el Teatro Teresa Carreño.

En relación con la actividad de los museos, se ha llamado la atención sobre el Museo de Arte Contemporáneo de Caracas (MACC), creado en 1974, por sus problemas debido a «la prohibición de realizar exposiciones individuales, la reducción de su presupuesto, la poca afluencia de público, la salida de investigadores; y la incertidumbre que ha existido en la dirección general del museo... los catálogos se acabaron. No se ha realizado ninguna exposición internacional», desde el año 2001, cuando su directora Sofía Ímber sale de su cargo (Falcón, 2010b: 3-10). Además, se ha revelado la desaparición de obras valiosas en 2002 y, en general, el informe de una empresa especializada que señalaba que «no existe una política para la toma física del inventario de obras de arte», aspecto que la Contraloría General de la República confirmó en 2004 al declarar que «no existe un récord de registro de movimientos de cualquier obra de arte» (Méndez, 2010: 20).

También se podrían citar los casos del Museo de Bellas Artes, creado en 1917, que ha perdido su autonomía para seleccionar sus propias exposiciones, convirtiéndose en sede de exhibiciones de otras instancias impuestas, 
como las efectuadas por la Biblioteca Nacional, el Banco Central, el Centro Nacional de la Diversidad (sobre juguetes y fiestas patronales), el Centro Nacional de Fotografía, el centro Nacional de Historia y hasta la Cancillería o Turismo (Esteva-Grillet, 2009: 20). Otro tanto ocurre con el Museo Narváez de Porlamar, que, al no disponer de aire acondicionado en sus instalaciones, los empleados sacan sus escritorios al jardín. Éste es uno de los ocho nuevos museos que el Ministro de Cultura había ofrecido crear desde 2006 fuera de la capital, todos los cuales fueron traspasados a la Fundación Nacional de Museos como una forma de ser más eficientes en su administración, todo a causa de falta de financiamiento (Falcón, 2010: 3-9).

En mayo de 2010, el Ministro de la Cultura Francisco Sesto, que reasumía su cargo, reconocía que los museos estaban en crisis. En reunión con los trabajadores de la Fundación de Museos Nacionales expresó que desde su creación en el año 2005, «el manejo de la fundación fue pésimo, porque creó un equipo por encima de los museos», aunque enfatizó que se mantendría la política de que los museos no posean colecciones, que desde hace 5 años éstas pertenecen a la Fundación y sólo son salas expositivas; así, por ejemplo, en el caso de Museo de Arte Contemporáneo (MACC), éste «no tiene colección, la colección es de la Fundación y del Estado. Los museos son una institución expositiva con autonomía para hacer las planificaciones. El MACC dejó de existir como institución». Pero, igualmente, hizo compartir parte de la crisis a los propios empleados de la Fundación, «a pesar de ser gratis, el pueblo lo ve como algo ajeno... El museo no es ajeno al pueblo, es que los trabajadores son ajenos a los museos. Cuando se inaugura una exposición ustedes no van» (Falcón, 2010a: 2-10).

También la historia tuvo sus problemas con el gobierno. El 5 de junio de 2010 la Academia Nacional de la Historia entregó al Archivo General de la Nación, los documentos del Generalísimo Francisco de Miranda, resguardados por 84 años, y los del Libertador Simón Bolívar, que mantuvo por 10 años. Hicieron entrega formal de estos documentos tres individuos de número de la Academia (Elías Pino Iturrieta, Inés Quintero y Marianela Ponce), expresando que cumplían con la obligación que tenían bajo coacción legal, agregando que la versión dada de que era un «secuestro y ocultamiento» de estos documentos no tenía base alguna. El Decreto 7375, emitido por el Presidente, en el cual expresaba que este acto era para «para lograr la mayor eficacia política y calidad revolucionaria en la construcción del Socialismo, la refundación de la nación venezolana... y con el objetivo de rescatar la memoria histórica de las luchas de liberación del pueblo venezolano, las cuales han sido ocultadas por factores políticos contrarios al proceso revolucio- 
nario», con lo cual se concretaba esta arbitrariedad en contra de dicha Academia (Hernández Cartstens, 2010: 4-8).

En cuanto al cine, la situación no es muy diferente. El informe entregado por Tulio Hernández (2008), sobre la Villa del cine, da luces al respecto. Según este crítico, en los diez años de este gobierno bolivariano se han realizado muy pocas películas, incluso de contenido político y las hechas como El caracazo, de Román Chalbaud, «son absolutamente incondicionales a las convicciones ideológicas del régimen», recordando que desde los años sesenta se producían películas críticas a los gobiernos con aporte oficial, como La ciudad que nos ve, documental de Enrique Guédez, de los sesenta, Cangrejo I y II de Chalbaud, de los años ochenta, en donde se muestra la corrupción abierta del poder judicial, Macu, la mujer del policía (1987) de Solveig Hoogesteijn — que superó en taquilla a todas las películas de EE. UU. exhibidas ese año, incluyendo a Superman - o Disparen a matar de Carlos Azpúrua, en los noventa, denunciando la violación de los derechos humanos. Contrario a esto, Secuestro Express (2005), de Jonatahn Jakubowicz, recibió amenazas de parte del gobierno y se le impidió que representara al país en la preselección del Oscar, por lo que el director se fue del país y no regresó. En 2006 el gobierno creó la Villa del cine, en la cual se ha filmado La clase, basada en una novela del entonces ministro de Cultura, en donde los pobres son buenos y los ricos malos. De las cuatro producciones realizadas, incluyendo Miranda, de Luis Lamata, de muy alto costo, ninguna ha permanecido en cartelera más de un mes en salas comerciales, y por orden directa del Presidente se otorgaron 18 millones de dólares a Danny Glover para una sola película extranjera, equivalente al presupuesto de tres años para financiar 15 películas nacionales. Esta villa es reseñada como un «centro encerrado en sí mismo, sectario y sesgado» (Ibid.).

Sobre estos aspectos, el Informe de la Comisión de Derechos Humanos (CIDH: 145) señala muy claramente lo siguiente:

«476. La CIDH ha señalado en reiteradas oportunidades que la censura previa es el prototipo de violación extrema y radical de la libertad de expresión, precisamente, porque "por medio del poder público, se establecen medios para impedir en forma previa la libre circulación de información, ideas, opiniones o noticias, por cualquier tipo de procedimiento que condicione la expresión o la difusión de información al control del Estado».

Los problemas del gobierno con la gente del teatro comienzan a sentirse en forma notoria y pública partir de año 2003, y su registro consta en los agu- 
dos informes que va entregando Luis Alberto Rosas (2005), tanto en su libro, que recoge información desde 2001 a 2004, como en sus comunicaciones digitales, correos electrónicos, de su red de la Asociación Venezolana de Licenciados en Teatro y Artes Escénica (ALIARTS). En el año 2003, Rosas (2005: 41-45) hace un urgente llamado a las autoridades para que el país participe en el IV Festival Internacional de Buenos Aires, en el cual «la representación venezolana brilla por su ausencia». Su argumento es que parece paradójico que un país como Argentina, que atravesaba por una de sus peores crisis económicas, pudiera organizar tal evento y no pudiera asistir el país que vivía un boom petrolero. Su explicación descarta que no haya grupos de calidad para representar al país, y tiende más bien a decir que «eso es culpa de este gobierno que hasta la cultura ha secuestrado». Igualmente sucede cuando reseña, en relación a los reconocimientos hacia las artes escénicas, que observa que lentamente van desapareciendo, recordando que «hasta entrada la década de los 90 existían por lo menos diez premios al año o bianuales» para reconocer a la gente del teatro, pero que en 2003 sólo existían cuatro premios. Ambas situaciones han tenido como respuesta del gobierno: «no se hizo más por falta de presupuesto», «la institución que lo entregaba desapareció» o peor aún, «la persona que motorizó ese premio murió», con lo cual se desestimulaba la creación.

El aspecto de las políticas culturales a implementar ya para 2008 se encontraba fuertemente politizado, como lo muestra el informe que dirige a la red cultural Beliza Castillo (2008), Directora de Cultura de la Alcaldía del Municipio Plaza, centro muy poblado aledaño a la ciudad de Caracas, quien expresó:

Quisiera contarles brevemente mi experiencia en la Dirección de Cultura de la Alcaldía del Municipio Plaza. No niego la responsabilidad que implicó para mi persona, aceptar tal cargo. Sabiendo de antemano el manejo extraño, inconvenientes, maltrato a los artistas y la situación política que se avecinaba. Todos sabemos que en buenos momentos a todos nos quieren y quien quiere algo, todo te ofrece y casi te lo da. Pero en «época» de salida, nada importa... todo está de más. He cometido muchos errores:

- Respetar mis principios y los de los demás.

- Tratar de incluir a aquellos apartados y apoyarlos como parte de nuestra sociedad.

- Tratar de repartir equitativamente, los recursos a las comunidades, artistas y centros culturales.

- Buscar incluir dentro de la planificación la opinión de los consejos comunales, artistas y cultores. 
- Dejar el despotismo, el amiguismo, el chantaje, la corrupción tanto en la administración como entre algunas agrupaciones culturales.

- Tratar de ser medianamente justa dentro del respeto.

- Tener un compromiso verdadero y sincero con el trabajo comunitario, con el socialismo, la igualdad, la honestidad y el humanismo.

- Darle oportunidades de superación a personas que, al parecer, fueron buenos actores. Mis aplausos para el equipo de Cultura. Primeros actores y actrices de este Municipio.

Pero como cada quien tiene lo que merece, yo me voy. Gracias a cada uno de mis errores... A todos mis queridos compañeros, geniales actores y actrices (personal de la Dirección de Cultura) que tanto esperaban un papel al menos de segundón... los felicito, sé y estoy segura, que nunca cometerán los mismos errores que yo he cometido. Sé que jamás serán juzgados, jamás tendrán problemas políticos, ya que son iguales al resto de los miembros de esta Alcaldía, al parecer personas que sí saben de este mundo. A todos mil disculpas...

Igualmente, no será fácil entender los criterios utilizados por el Ministerio del Cultura en la asignación de sus financiamientos. Tal vez, lo más explícito sea remitirse a los documentos de los propios afectados, cuya mejor aproximación a los criterios y procedimientos utilizados la ilustra el caso del grupo Teatro del Duende, con 54 años de existencia, en donde la figura central es el dramaturgo afecto al gobierno Gilberto Pinto, a quien el propio Presidente le entregó su Premio Nacional de Teatro en 1999, y a su esposa Francis Rueda, también premiada por el gobierno, pero a quienes se les negó financiamiento por ser considerado su grupo, «caso excepcional» (ALIARTS, 2009):

Argumento que no entendimos hasta enterarnos (con un asombro aún mayor) de los criterios que rigen para el otorgamiento de los llamados «Convenios de Cooperación Cultural». Criterios excluyentes, censores y anticonstitucionales, que no nos explicamos cómo pueden ser asentados con carácter de legalidad por el Ministerio de Cultura de un país que se considera socialista, y que sólo pretenden obtener la aceptación sumisa, gracias a un arbitraje impuesto por un reducido grupo de subalternos desconocedores de lo que es el teatro y su relación con la cultura. $Y$, sobre todo, con visible irrespeto a sus hacedores, a quienes la nación les debe un agradecimiento por los muchos años dedicados al servicio del mundo espiritual e intelectual de los venezolanos.

Pasamos a destacar el contenido del Criterio 2, que se refiere a los «Casos Excepcionales»: 
a. No se financiarán a colectivos e individualidades cuyas conductas públicas perniciosas, afecten la estabilidad psicológica y emocional colectiva de la población, haciendo uso de un lenguaje ofensivo, descalificando, mintiendo y manipulando a través de campañas mediáticas dispuestas para tales fines. (Esta acción quedará a juicio facultativo de la Mesa Técnica Estatal). Toda la redonda de este insólito criterio es nuestra.

Trataremos de analizar cada uno de los contenidos de esta decisión y preguntarles a los miembros no identificados de esa Mesa Técnica en cuáles de esos «casos excepcionales» involucraron a nuestra agrupación.

Conducta perniciosa: ¿Distribución o tráfico de drogas? ¿Trata de blancas? ¿Pornografía infantil? ¿Promiscuidad sexual? ¿Alcoholismo? ¿Violación? ¿Exaltación a la delincuencia? ¿Sicariato? ¿Corrupción? ¿En cuál?, preguntamos.

Afectación de la estabilidad colectiva de la población: ¿Incitación a la rebelión? ¿Respaldo al terrorismo o al magnicidio? ¿Promoción del Guarimbeo? ¿Al cierre de avenidas? ¿Al saqueo? ¿Al linchamiento? ¿Al irrespeto a la dignidad presidencial? ¿En dónde estarían las pruebas de tales afectaciones?

Lenguaje ofensivo y descalificador: Si se hubieran tomado la molestia de leer alguna de las veinte obras escritas por nuestro director, no hubiesen encontrado ni rastro del estilo Nolia o Silva. Lo mismo decimos de nuestras declaraciones a la prensa, en donde, de manera respetuosa, demandamos del gobierno su acatamiento a la Constitución y a la Declaración de los Derechos Humanos en el sentido de que amplié su apoyo a la cultura, de la cual todo ciudadano tiene derecho a disfrutar.

Mintiendo y manipulando campañas mediáticas: ¿En dónde? ¿En nuestros espacios políticos de la televisión? ¿En nuestras columnas fijas de la prensa nacional? ¡Que consideración más pueril!!!!! Sin esas tribunas no se pueden hacer campañas desestabilizadoras. El teatro no cuenta sino con el escenario para manifestarse. Y en ese sentido el Teatro del Duende jamás lo ha utilizado como panfleto político, porque considera que eso sería rebajarlo estética y socialmente. El teatro es una instancia superior de la cultura. Destinada a transformar a los transformadores del ente social. Calificar, si éste es el caso, a nuestra institución de mentirosa es de una total impostura. ¿Entonces? ¿Qué es lo que se persigue con juicios amañados como éste? ¿Qué uno se nulifique, que se haga indistinguible del rebaño? ¿Qué uno pierda su individualidad? Sería necesario que recordaran a la camarada Rosa Luxemburgo: Sin una lucha libre de opiniones, la vida se muere en toda institución pública (negritas del original).

Pinto recuerda que, al recibir el Premio Nacional, le dijo al Presidente: «si no apoya la cultura, volveremos a la jungla», agregando luego, en entre- 
vista con Mireya Tabuas (2009), que «el problema con el chavismo es que te ponen una etiqueta y te cosifican. Ya lo decía el maestro Simón Rodríguez, a quien no se atreverán a calificar de mentiroso y manipulador: "Nunca se hará República con gente ignorante"». Al consultársele sobre las manifestaciones culturales o teatrales que apoya el gobierno, respondió: «El de diversión. Los funcionarios chavistas consideran que divertirse significa no pensar, por eso producen una serie de espectáculos muy divertidos para que la gente no piense», por esta razón, la Dirección de Teatro pasó a ser de Teatro y Circo, lo cual confirmó Pinto: «Sí, ¡cómo han apoyado al circo! Dejó de hacer festivales de teatro para organizar unos de circo y de salsa. Para los chavistas, lo que no hace pensar es lo más conveniente, pero eso es una degeneración de lo que necesita la sociedad. Es una de las cosas que los que hacemos teatro de arte no aceptamos. El Gobierno cree que el arte es elitesco... Cada vez que veo un espectáculo planteado por ellos, veo un folklorismo tratado con poco brillo. Hay un folklore popular que debe ser apoyado, no lo estoy negando. Pero el folklore no puede ser el todo cultural de un país, porque la cultura es una superestructura del conocimiento... Esa medida (en contra de su grupo) tiene carácter de censura, de exclusión y es anticonstitucional. Calificar de pernicioso a un artista es indignante, más aun cuando viene de un grupúsculo de monomaníacos del sistema que no toleran la más pequeña crítica de su gestión, pues mi único desliz pernicioso ha sido reclamar - cosa que seguiré haciendo - mayor apoyo a la cultura, tal como obliga la Constitución».

Lo mismo podría decirse también de los grupos de teatro afectos al oficialismo que reciben algún subsidio del Instituto de las Artes Escénicas y Musicales (IAEM), ente adscrito al Ministerio de la Cultura, quienes tienen «terminantemente prohibido reproducir en el programa de mano los logos de los periódicos Tal cual y El Nacional, así como de la planta televisiva Globovisión», que han auspiciado de alguna manera sus obras; ante lo cual estos grupos «han tenido que imprimir un doble tiraje del programa de mano: unos con patrocinantes oficiales y otros con patrocinantes privados»; los primeros los presentan al gobierno para evitar perder su subsidio del Estado y los segundos a los espectadores, con lo cual no pierden la ayuda de esos medios de comunicación (Política, 2010: 9).

La misma situación ha ocurrido con varias puestas en escena de la empresa teatral Palo de Agua Producciones, cuando en marzo de 2009 al poner en escena la obra El violinista en el tejado, en forma anónima, le comunicaron a la productora que la Orquesta Gran Mariscal de Ayacucho se retiraba del proyecto por ser una obra judía que les hacía peligrar el subsidio del go- 
bierno y, aunque la versión fue negada por la orquesta, los productores tuvieron que buscar otra orquesta para acompañar la obra; en otra ocasión la empresa fue vetada para utilizar la sala del Teatro Teresa Carreño, a pesar de sus solicitudes escritas, hasta que un funcionario les dijo: «dejen de escribirnos, porque no vamos a darles la sala». En forma similar, en ocasión de la producción de la obra Jesucristo Superestrella, en 2010, en el Aula Magna de la Universidad Central de Venezuela, luego de recibir la confirmación formal del patrocinio de la obra por las empresas del Estado Movilnet y Balckberry Rim, se les informó de una nueva y definitiva condición del acuerdo, la cual les prohibía «pautar cualquier tipo de publicidad paga o realizar algún tipo de alianza comercial con los siguientes medios de comunicación: Globovisión, El Nacional, El Universal, El Nuevo País, Tal Cual, Revista Zeta y Ateneo $F M »$ y que sólo debía llegar a acuerdos con «aquellos medios que las empresas Blackberry y Movilnet aprobasen», argumento que la productora desechó y consideró inadmisible por estar motivados por criterio político «cuestionable profesionalmente, comercialmente y éticamente... Aceptarlo iría en contra de nuestros principios y de los que deben guiar el comportamiento responsable de las personas y las organizaciones en una sociedad libre y democrática» (Cotoret, 2010c).

La situación se tornó más complicada aún cuando durante sus presentaciones, el domingo 1 de marzo de 2010, casi al finalizar su temporada y cuando estaba por terminar la función, desconocidos lanzaron dos bombas lacrimógenas hacia el sótano del teatro, afectando solamente a parte de la orquesta que se ubica en ese nivel, sin mayores consecuencias para la audiencia que no se percató del hecho por la acción de los equipos de seguridad. La empresa expresó no poder determinar si el incidente era en contra del espectáculo o «iba dirigido a la rectora de la Universidad, Cecilia Arocha, quien se encontraba en el lugar». Este teatro universitario se ha transformado en un centro cultural dada la escasez de salas y las restricciones para poner en escenas obras por parte del gobierno, por ello el Aula Magna de la Universidad en la práctica se ha convertido en el epicentro cultural y político más importante del país en estos años. Es éste uno de los pocos casos en que la censura del gobierno no sólo fue rechazada por una empresa teatral, sino que, además, la perversa intimidación fue hecha pública con todos sus detalles, sin ser desmentida por ente oficial alguno (Cotoret, 2010b: 25 y Rodríguez, 2010: 19).

El procedimiento para aplicar los convenios de subsidio y financiamiento deriva de un acuerdo entre un ente gremial de los teatreros, la Fundación Red Nacional de Teatro y Circo de Venezuela (Renacit) y el Ministerio de la 
Cultura, por medio del cual, para efectos de la decisión sobre los financiamientos, participaban un vocero de la comunidad o área artística del teatro y circo, en las 24 entidades del país. Estas entidades se llamaron «mesas técnicas», que resolvían sobre los Convenios de Cooperación Cultural en 2009, y que las conformaban los gabinetes ministeriales Estatales de Cultura, voceros de los consejos comunales, voceros de las salas de Batalla Social, de la Red de Creadores y voceros de los sectores y comunidades artísticas, teatro, danza y música. La función de estas mesas técnicas, según Gregorio Magdaleno y Guillermo Díaz, del Distrito Capital, era la de informar a las agrupaciones de los planteamientos de los Ministerios y ver el cumplimento de los grupos con los criterios de asignación, en un contexto de reconducción presupuestaria de 2008. Según esto, se tomaba la decisión de asignar o no este subsidio. En el caso del Distrito Capital, el más crítico, se eliminaron estos subsidios a varios grupos teatrales, como se verá más adelante.

En el acta con los Resultados de las Mesas Técnicas en los Convenios de Cooperación Cultural 2009, Plataforma de Artes Escénicas y Musicales del Ministerio de la Cultura, con fecha entre 24 y 27 de agosto, se deja constancia de que sólo 53 grupos «concuerdan con las políticas culturales del Ministerio de la Cultura y con impacto social comunitario», y a 23 agrupaciones se les excluyó de los convenios de este año por no estar «apegadas a las políticas culturales» o por «la ausencia de rendiciones en el tiempo acordado para ello de los Convenios de Cooperación Cultural 2008» (De interés, 2009)

Tras veinte años de actividad, de investigación y experimentación teatral, en 2008 el grupo Teja recibió orden de desalojo de su sede en el teatro Alberto de Paz y Mateos, sector Las Palmas de Caracas, por orden del Ministerio de la Cultura, sin mayores explicaciones, cuando vencía su comodato de la sala, además de dejarlos sin subsidio. Esta institución había sido declarada Patrimonio Cultural por el Concejo Municipal Libertador en 1999. La medida de desalojo no sólo afecta a Teja, sino también a otros grupos que tenían su sede en este teatro, como Caracas Roja Laboratorio, Macrodanza, el programa infantil del Ballet Contemporáneo de Caracas Ven a danzar y al Teatro el Laberinto, del Centro de Investigación sobre la Danza Tradicional Venezolana de Fundafolk (ALIARTS, 2008). Parte de esta decisión, según su director, José Simón Escalona, se debería a «que yo sea un hombre de RCTV. Además, estoy en la oposición, donde he estado durante todos los gobiernos... hay retaliación contra todo el que piense distinto, contra el que no quiere alienarse con el discurso oficial, contra el que no se somete. Y no hay retaliación únicamente: hay violencia... No nos manejamos por el principio de la complacencia. Nuestro teatro es incómodo» (Bell, 2009: 3). 
Su último montaje en esta sede fue La divina comedia de Dante Alighieri, que intenta retratar a una sociedad italiana medieval corrompida, exponiendo con profundidad la crisis del final de esa época, especialmente de su cultura, «los venezolanos nos hemos labrado nuestro infierno actual... no fuimos capaces de entender la trascendencia y la importancia de la democracia... No hay que olvidar que la intención del autor es moralizante. Se pueden vencer los obstáculos...» (Villamizar, 2009: 3-8).

2008 fue el año de las sorpresas que preparaba el gobierno. A principios de año, al presentarse la obra Todos los hombres son mortales y las mujeres también, en el Centro de Estudios Latinoamericanos Rómulo Gallegos (CELARG), la actriz Fabiola Colmenares «fue vetada por el CELARG por su postura política abiertamente opuesta al gobierno». Su director, Héctor Manrique, se negó a aceptar tal censura que exigía retirar a la actriz del elenco para poder exhibirla en esa sala. Luego de lo cual Manrique fue considerado por el gobierno como «pernicioso», con lo cual se le negó cualquier subsidio.

Igualmente, Marcos Purroy, autor y director de la obra Hollywood Style, «cedió a los requerimientos del CELARG de suprimir algunas improvisaciones y frases del parlamento de su montaje que pudiesen herir al gobierno». El año 2008 fue considerado por los críticos como «el más lamentable del ex ministro de Cultura Francisco Sesto: menospreció al gremio y lo asfixió» $\mathrm{y}$ «lo más lamentable es que cada día tenemos menos espacios» (Bell, 2008: 4 y ALIARTS, 2008). Anteriormente, en 2006, cuando la dramaturga Genny Pérez obtuvo veredicto ganador del jurado al Premio de dramaturgia del Ministerio de la Cultura, por su obra Yo soy Carlos Marx, este Ministro hizo infructuosos esfuerzos por anular el premio, sin éxito, aunque la obra fue publicada por una editorial del Estado.

En esta política de censura, negando el financiamiento a los grupos teatrales por parte del Ministerio de la Cultura, según los criterios que adoptó la Mesa Técnica del Estado Miranda, cayeron los grupos Skena, Bagazos y El Duende, considerados «casos excepcionales», por lo que «no se financiarán a colectivos e individualidades (sic) cuyas conductas públicas perniciosas afecten la estabilidad psicológica y emocional colectiva de la población, haciendo uso de lenguaje ofensivo, descalificador, mintiendo y manipulando a través de campañas mediáticas dispuestas para tales fines (Cotoret, 2010: 24).

De la Mesa Técnica del Distrito Capital surgió el mismo problema con los grupos Theja, Cénica, Entretelones, Bagazos, Art-O de Caracas, Contrafuego y Convención Internacional de Circo. En el caso del grupo Actoral 80, 
cuyo director es Héctor Manrique, se aplicó la claúsula 2 de las condiciones del Convenio de Cooperación 2009, que se refiere a las conductas perniciosas expresadas en campañas mediáticas que ocasionen zozobra en la población, lo cual es causal de exclusión de los Convenios. Esta opinión crítica del director del grupo, respecto de algunas decisiones sobre la política cultural del gobierno, fue el argumento de la institución gubernamental, la cual no fue compartida por los miembros de la Mesa Técnica, quienes acordaron elevar la situación a una nivel superior del Ministerio de la Cultura para su decisión (Ibid.).

El cerco oficial existe no sólo en el financiamiento y en los subsidios, tal como lo expone Héctor Castro (1986) al expresar su denuncia sobre la censura en otra institución el Estado, según lo muestra Ángel Ricardo Gómez (2008:3-8):

Tú vas al CELARG y leen primero el texto y si ese texto les gusta o levanta la taquilla, ellos lo aceptan. Yo quise montar una pieza que se llama «Concierto en re para dos panas burda», una obra cantada que se ha ganado dos premios, y no pude. En esa obra yo cuento cómo fue el secuestro de Niehaus. Ese caso lo descubren por la delación de uno de los secuestradores y ese delator está ahora en el Ministerio de la Cultura, no se dice el nombre de él, pero la gente va a saber que es él... Los dramaturgos estamos contra la pared... A nosotros no nos montan, no nos publican, he hablado con directores venezolanos y te dicen que montarnos es un riego. Prefieren montar autores extranjeros que a nosotros.

Uno de los casos que ha tenido mayor trascendencia ha sido el desalojo del Ateneo de Caracas de su sede. En mayo de 2009, el Ateneo dejó su sede, frente a la Plaza Morelos, en el centro de la ciudad, después de 77 años de labor permanente. El vencimiento de un comodato y las malas condiciones del local fueron la excusa. En este edificio funcionaban varias organizaciones culturales como la Federación de Ateneos de Venezuela (Fedeateneos), Amnistía Internacional (AI) y los grupos Contrafuego y Naku — con una trayectoria de 20 años y que ya tenía dos años sin recibir subsidio del gobierno-. Meses antes, el día 20 de enero, mientras se realizaba en sus alrededores una protesta estudiantil y en el interior se celebra el 38 aniversario del grupo político Bandera Roja, un grupo de simpatizantes el Partido Unidad Popular Venezolana, dirigidos por Lina Ron, irrumpió violentamente en contra de los estudiantes en el interior, arrojando bombas lacrimógenas. Ron admitió estos hechos: «Las autoridades del Ateneo tienen concentrados allí a toda la gente de la ultraderecha...» La representante oficialista hizo un 
llamado al ministro de Cultura, Héctor Soto, para que los apoye, pues «las instalaciones del Ateneo están tomadas por grupos de la ultraderecha, y por instrucciones mías van a ser tomadas ahora por la revolución» (Tal Cual, 2010).

Después del cierre del Ateneo, figuras de la cultura suscribieron un manifiesto que rechazaba «la reiterada persecución política desatada por el ministro de la Cultura, arquitecto Francisco Sesto, en contra de algunos ateneos independientes de Venezuela y en su particular ensañamiento contra el Ateneo de Caracas». En esa oportunidad, también se anunció la suspensión de la XVII edición del Festival Internacional de Teatro de Caracas. Manrique manifestó: «Los que echo de menos son voces oficiales, pero compañeros artistas: no entiendo por qué Román Chalbaud no dice una palabra. O Rodolfo Santana, que estrenó varias piezas en el Ateneo. Son dos voces fuertes, dos dramaturgos importantes del país. Su silencio no habla bien de ellos, y creo que en el fondo es ser mezquino con uno mismo, que es la peor mezquindad que puede haber, y con su historia. Hasta para estar en contra me gustaría escuchar esas voces» (Hernández, 2009). Sobre el cierre del Ateneo de Caracas, así como sobre la violencia ejercida por «grupos de choque», el informe de la Comisión Interamericana de Derechos Humanos (CIDH: 147-148) dedica un capítulo de resolución especial.

\section{PALABRAS FINALES}

Hernández ha dividido este decenio en tres períodos culturales: el primero, aparte de la designación fallida de Luis Britto que sólo duró horas y que estableció una guerra intestina, lo denomina Mandela, inicial, bajo la tutela de Alejandro Armas, «de transición y respeto a las personalidades culturales», quien conformó un directorio de relativo consenso con Benito Irady, Igor Delgado S., Domingo Miliani y Antonio López Ortega y que tuvo que abandonar al régimen por disputas internas; el segundo, denominado Salomé, a cargo de Manuel Espinoza, colaborador de Armas, acusado por éste de conspirar en su contra luego que apareció el 16 de noviembre de 1999 la revista Primicia en la cual se efectuaba un «cuestionamiento severo a la gestión de Alejandro Armas» (Dahbar, 1999: H-7); este período breve también lo denominó «revolución cultural» y que se encargó de descabezar al sector cultural, y entregó la cabeza de «Sofía Î́mber, María Elena Ramos y un grupo de autoridades culturales»; y el tercer período, el de ministro Francisco Sesto, que denominó «los tiempos del comisario cultural», caracterizado por la «impro- 
visación, el personalismo que se ha movido entre los caprichos del Presidente y Farruco... y la falta de intelectuales». Con él comenzaron «las purgas contra funcionarios y artistas subvencionados incluidos en la lista Tascón o de laxa observancia a la ideología oficial», quien se estrenó de censor con su veto a los ya seleccionados artistas para la Bienal de Venecia, a quienes acusó de «incitar con sus cuadros al magnicidio» (Pasquali, 2005: A-12).

Carentes de un proyecto cultural firme, se abre paso a espectáculos de evasión -incluso de autores opuestos al régimen-, que se consideran exponentes idealizados y añorados de tiempos que no vendrán, comedias u otros géneros, que siempre supone instalar una ruptura con la abrumadora realidad cotidiana, para presentar una visión ideal o de fantasía, en donde ni las situaciones, ni los personajes, ni la propia lógica, tienen que ver con el diario vivir que hay que ocultar.

Se hace evidente que la censura es una práctica del poder que se autoasigna el derecho para «condenar al silencio el deseo y la propuesta de un autor», con todas sus consecuencias económicas, sociales y judiciales (Berenguer (2008: 17). Es, sin duda, en Venezuela una actividad ilegítima - aunque aparentemente se utilicen o prueben ser legales-. Es, para decirlo en términos más reflexivos, entrar en el espacio oscuro en que se mueve y actúa un poder que se considera a sí mismo como absoluto, en contra de una sociedad que tiene ideales distintos a los del régimen, que de alguna forma lo cuestionaba en sus obras censuradas.

Todos los autores, ideas y obras presentadas en esta investigación, son sólo una muestra de lo conocido, son una generosa invitación que ellos hacen para conocer esta historia oculta de la cultura venezolana, aún por develar completamente, y que es como abrir una puerta que por mucho tiempo ha permanecido cerrada y vedada. Sólo en la medida en que se descubra este velo con investigaciones audaces que lo profundicen y denuncien se perderá de una vez por todas el miedo a esta inoportuna invitada que ha sido la censura. Pero, también, desde ahora, se debe entender perfectamente que los autores y obras censuradas fue uno de los terrenos importantes en donde se luchó en contra del autoritarismo.

\section{REFERENCIAS BIBLIOGRÁFICAS}

ALIARTS (2009). «Aclaratoria a la comunidad teatral». Comunicación personal por e-mail del 23 de octubre. 
- (2008). Comunicación personal por e-mail del 21 de junio.

ALTEZ, Rogelio (2000). «Desastres y conocimiento». En Visiones del oficio, José A. Rodríguez (ed.), 453-474. Caracas: Universidad Central de Venezuela.

APORREA (2004). «Debate sobre Ley resorte». En www.aporrea.org/ actualidad/a10467.html (Consulta: 18.02.2010).

- (2009). Foros de Aporrea.org: Ver tema - Acerca de Trapiello y lo de TVES... En www.aporrea.com/forum/viewtopic.php? $p=251141$ (Consulta: $18 / 02 / 10)$.

BÁEZ, Fernando (2004). Historia universal de la destrucción de los libros. De las tablillas sumerias a la Guerra de Irak. Barcelona: Destino.

BELL, Marco (2009). «El foro del lunes». El Nacional, 26 de enero, 3 («Cultura escenas»).

- (2008). «Balance». El Nacional, 24 de diciembre, 4.

BERENGUER, Ángel (2008). «Deseos expresados, deseos (indeseados. Sistemas y procesos para el control de las estrategias creativas del YO en la sociedad contemporánea». Teatro 22 (Segunda época), diciembre, 15-26.

CABALLERO, Manuel (2010). «Se puede ser marxista y bolivariano». El Universal, 12 de febrero, 4-8.

CAÑIZALES, Andrés (2010). «La AN y las libertades». Tal Cual, 19 de enero, 18.

CASTILLO, Beliza (2008). Comunicación personal por e-mail del 14 de septiembre.

CASTRO, Héctor (1986). Concierto en re mayor para dos panas burda. Maracay: Casa de la Cultura.

CHESNEY LAWRENCE, Luis (2008). «La censura en el teatro venezolano (1900-1960)». Teatro 22 (Segunda época), diciembre, 77-118.

COMISIÓN INTERAMERICANA DE DERECHOS HUMANOS (CIDH, 2009). Democracia y Derechos Humanos en Venezuela. Informe del 30 de diciembre. En http://www.cidh.org/.

COTORET, Martha (2010a). «Espacios politizados». Tal Cual, 1 de marzo, 24.

- (2010b). «Jesucristo bombardeado». Tal Cual, 9 de marzo, 25. 
- (2010c). «Censura publicitaria». Tal Cual, 26 de febrero, 32.

DAHBAR, Sergio (1999). «La cultura sigue siendo una piedra en el zapato de Chávez». El Nacional, 21 de noviembre, H-7.

DE INTERÉS (2009). El Universal, 30 de septiembre. En http://www.grupoactoral80.com/deinteres-subsidios4.html (Consulta: 30/03/2010).

DOCUMENTO POLÍTICO DEL FRENTE DE JUVENTUDES BICENTENARIAS 200 (2010). En http://juventud.psuv.org.ve/ (Consulta: 18/04/2010).

DOVALE PRADO, Luis (2009). Coro: la tragedia de un memoricidio. Coro: Universidad Nacional Experimental Francisco de Miranda / Fundación Oscar Beaujón Graterol.

ESTEVA-GRILLET, Roldán (2009). «Artes versus turismo». Tal Cual, 27 de octubre, 20.

FALCÓN, Dubraska (2009). «María Eugenia Barrios cree que Min. Cultura cometió un error». El Universal, 17 de octubre, 2.-12.

- (2010a). «Museos sin destino». El Universal, 17 de enero, 3-9.

- (2010b). «MACC: bajo las sombras». El Universal, 10 de enero, 3-10.

GIL YEPES, José A. (2009). La centro democracia. Tomo I. Caracas: Ed. El Nacional.

GIUSTI, Roberto (2010). «La ola de derecha impedirá que Chávez haga estallar la OEA». El Universal, 28 de febrero, 1-2.

GÓMEZ, Ángel Ricardo (2008). «Teatro contra la pared». El Universal, 8 de junio, 3-8.

HERNÁNDEZ, Ana María (2009). «No debe permitirse la censura». El Universal, 2 de marzo, 4-8.

HERNÁNDEZ, Tulio (1999). «Escritores de una duda». El Nacional, 24 de octubre, H-3.

- (2007). «El crimen de pensar con libertad». El Nacional, 18 de febrero. En http://www.asovac.org/2007/02/18/el-crimen-de-pensar-con-libertad-por-tulio-hernandez/ (Consulta: 18/02/2010).

— (2008). «La villa del mal (cine)». El Nacional, 14 de septiembre: Sietedías-7. 
HERNÁNDEZ CARSTENS, Eduardo (2010). «Los archivos de Bolívar». El Universal, 6 de junio, 4-8.

INSTITUTO DE PRENSA INTERNACIONAL (IPI) (2009). «Visita del IPI a Venezuela». El Universal, 22 de noviembre, 1-4.

IZARRA, Andrés (2008). «...y todo lo demás: Socialismo del siglo XXI y censura: Hegemonía...». En ytodolodemas.blogspot.com/.../socialismodel-siglo-xxi-y-censura.html (Consulta: 18/02/10).

LUBRIO (2009). «El espacio de Lubrio». En http://lubrio.blogspot.com/ 2009/12/la-censura-de-los medios-del-estadoal.html (Consulta: 05/12/2009).

LUCIEN, Óscar (2006). «La cultura en la Revolución bolivariana». El Nacional, 8 de junio, A-9.

MÉNDEZ, Carmen Victoria (2010). «Los misterios del MAC». Tal Cual, 10 de enero, 20.

PASQUALI, Antonio (2005). «La cultura del régimen». El Nacional, 17 de julio, A-12.

PIÑERO, Leda (2009). Periodistas de la Cadena Capriles aclaran que son víctimas y no... En www.eluniversal.com / Nacional y Política, 18 de agosto (Consulta: 20/02/2010).

POLÍTICA (2010). «Ni a la esquina». Tal Cual, 5 de marzo, 9.

REYES, Óscar (2001). «Burocracia cultural y esquizofrenia de los creadores». En Analitica.com (Consulta: 20/07/2001).

REYES, Theis (2010). «CONATEL reinició medias de cierre a emisora de radio». El Universal, 16 de enero, 1-4.

RODRÍGUEZ, Héctor (2010). «Guerrilla comunicacional». En http://juventud.psuv.org.ve/index.php (Consulta: 26/04/2010).

ROSAS, Luis Alberto (2005). En primera fila. Caracas: Ed. ACTUM.

SERRANO LÓPEZ, Wladimir (2006). «Dossier y la lucha contra la corrupción». En www.aporrea.org/medios/a21077.html (publicado el 13/04/06).

SINDICATO NACIONAL DE TRABAJADORES DE LA PRENSA (2010). «Medidas contra televisoras por cable restringe aún más la libertad de información». El Universal, 24 de enero, 1-9. 
SOTO, Fabiola (2008). «Deprave mediático oficialista en la mira internacional». En www.versionfinal.com.e/wp/2008/03/28/deprave-mediticooficialista-en la mira internacional/.

TABUAS, Mireya (200). Entrevista a Gilberto Pinto. El Nacional, 1 de noviembre. En http://www. grupoactoral80.com/deinteres-gilbertopinto.html (Consulta: 30/03/2010).

TAL CUAL (2010). «Obra de Lina y su pandilla». Talcualdigital.com (Consulta: 20/01/2010).

VILLAMIZAR, Simón (2009). «El infierno de Teja». El Universal, 27 de septiembre, 3-8.

Recibido el 28 de enero de 2011.

Aceptado el 22 de septiembre de 2011. 